Journal of Advanced Research in Fluid Mechanics and Thermal Sciences

\title{
Optimization of Reaction Conditions for Hydroxypropylation of Saba Banana Starch
}

\author{
Jau-Shya Lee ${ }^{1,}{ }^{*}$, Pamela Chin-Shin Loh ${ }^{1}$, Ramlah George ${ }^{1}$, NurDiyana Yusoff ${ }^{2}$ \\ Faculty of Food Science and Nutrition, Universiti Malaysia Sabah, Jalan UMS, 88400 Kota Kinabalu, Sabah, Malaysia \\ Agriculture Research Centre, Department of Agriculture Sabah, 89207 Tuaran, Sabah, Malaysia
}

\section{ARTICLE INFO ABSTRACT}

Article history:

Received 29 October 2020

Received in revised form 5 January 2021

Accepted 9 January 2021

Available online 15 February 2021

Keywords:

Banana starch; hydroxypropylation; pasting properties; freeze-thaw stability; thermal properties; RSM

\section{Introduction}

Bananas are the most produced fruit in Malaysia with the average self-sufficiency ratio of $103 \%$ between 2013 and 2017. In 2017, the planted areas cover 35,000 hectares ( $\mathrm{Ha}$ ) and the production was more than 350,000 metric tonnes and accounted for $24 \%$ of Malaysia's total fruit production in that year [1]. Among the states in Malaysia, Sabah which is located in the north of Borneo Island is one of the main banana producers. The most widely planted cultivar in Sabah is Saba banana (Musa acuminata $\times$ Musa balbisiana). Saba banana is a cooking banana and often eaten steamed, deepfried (banana fritters) or made into other traditional snacks by the local community. Besides

\footnotetext{
*Corresponding author.

E-mail address: jslee@ums.edu.my
}

https://doi.org/10.37934/arfmts.80.2.8297 
internally consumed, the fruit is also exported to other states of Malaysia. Currently, the industrial applications of Saba banana are limited to the small scale production of banana crisps and banana flour. In recent decades, the promotion of regional economies by different worldwide agencies and the search of sustainable agricultural activities have motivated the exploration of alternative starch botanical sources, despite the traditional cereals and tubers. Starches from tropical fruits like banana have attracted attention due to the high starch content [2]. Owing to banana's highly perishable nature and considerably large quantities of lost by postharvest mishandling, converting banana at early maturity stage into starch can be a feasible solution to reduce banana waste [3].

In food industry applications, the functionality of starch is largely related to its gelatinization, pasting and retrogradation characteristics, but it is well established that starch in its native form have many shortcomings that cannot fulfil the required functionalities. For successful industrial applications, the deficiencies of native starch ought to be overcome by starch modification that may be accomplished by genetic, physical, chemical or enzymatic methods. Hydroxypropylation is a chemical modification of starches that introduces hydroxypropyl groups onto the polymeric chain of starch using propylene oxide as the etherifying reagent in the presence of an alkaline catalyst to facilitate the formation of nucleophilic starch- $\mathrm{O}^{-}$alkoxide [4]. The substitution mainly takes place at three hydroxyl groups adjacent to the carbon atoms at 2, 3 and 6 positions in each anhydroglucose unit (AGU) [5] as shown in Figure 1. Hydroxypropylation of starch is classified as stabilized starch because the substituted ether groups are completely stable in both acidic and alkaline environments. Hydroxypropylation also reduces the tendency of starch pastes and gels to retrograde, while maintaining the ability of the starch to provide bulk, body, and other functionalities to the food products. This modified starch pastes and gels have less opacity and more pleasant texture, undergo less syneresis, more tolerant to cold storage as well as more freeze-thaw stable [6].

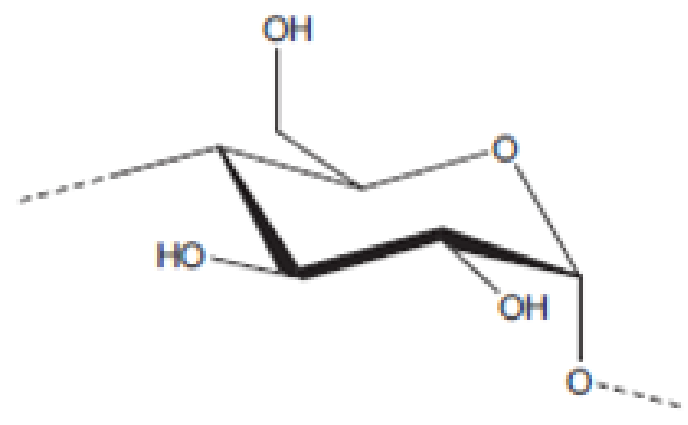

Fig. 1. Three hydroxyl groups adjacent to the carbon atoms at 2, 3 and 6 positions in an anhydroglucose unit of starch

In order to add value and enable wider applications of Saba banana, this study was aimed to optimize the reaction conditions for hydroxypropylation of Saba banana. Though extensive studies on hydroxypropylation of various kinds of starch are reported in the available literature, the reactivities and properties of resulted hydroxypropylated staches may vary by the botanical origin of the starch due to the variations in the molecular and granular structures and also the starch properties [6]. Hydroxypropylation conditions that involved the reaction $\mathrm{pH}$, reaction temperature and quantity of propylene oxide were investigated. Our earlier work [7] reported degree of hydroxypropylation (molar substitution, MS) was significantly correlated to several important functionalities of modified Saba banana starch, such as freeze-thaw stability, pasting properties and 
thermal behaviour; along with brief discussion on the influence of the above mentioned reaction conditions on the functionalities. Differ from previous report, this work elaborated the mathematical models obtained using Response Surface Methodology (RSM) for each of the investigated response; the optimization was also carried out to achieve more specific desirable functional properties. The validation of model was performed, follows by comparison of desirable functional properties between hydroxypropylated and native starch for verification purpose. Proper uses of design of experiments and statistical approaches have been reported effective and beneficial in optimizing various process parameters $[8,9]$.

\section{Methodology}

\subsection{Materials}

Matured but unripe (total green peel colour) Saba banana (Musa acuminata x Musa balbisiana) was obtained from a local orchard in Keningau, Sabah, Malaysia. All chemicals used were of reagent grade or USP grade (as specified under respective sections) and were used as received without any further purification.

\subsection{Isolation of Banana Starch}

Starch isolation was carried out according to Nimsung et al., [10] with slight modification upon arrival. The pulp was peeled, sliced ( $0.5 \mathrm{~cm}$ thick) and dried in a hot air oven at $50{ }^{\circ} \mathrm{C}$ for $24 \mathrm{~h}$. The dried chips were milled and pass through a 100-mesh sieve to obtain the flour. After that, the flour was suspended in $0.05 \mathrm{~N} \mathrm{NaOH}$ (Systerm, SO460-70, AR) with 1:5 ratio (flour:solution) and homogenized using over-head stirrer $(500 \mathrm{rpm})$. The slurry was centrifuged to obtain the sediment. The sediment was washed with distilled water (1:2) prior to centrifugation at $3000 \mathrm{rpm}$ for $20 \mathrm{~min}$ at room temperature. The washing procedures were repeated three to four times. The $\mathrm{pH}$ of starch slurry was adjusted to 7.0 prior to the last round of centrifugation. The purified sediment was ovendried at $50{ }^{\circ} \mathrm{C}$ overnight to obtain a white powder. The dried powder was ground to pass through 200 mesh sieve and stored in an air-tight container at room temperature until further use.

\subsection{Experimental Design}

A Central Composite Design (CCD) was employed to determine the relative contributions of three independent variables on hydroxypropylation of Saba banana starch. The three independent variables were the amount of propylene oxide $(5 \%, 10 \%$ and $15 \%, \mathrm{v} / \mathrm{w}$ of starch dry weight, equivalent to $3,6,9 \mathrm{~mL})$, reaction $\mathrm{pH}(10,11$ and 12$)$ and reaction temperature $\left(35,40\right.$ and $\left.45^{\circ} \mathrm{C}\right)$. The responses measured were molar substitution, pasting properties, freeze-thaw stability and thermal behaviour. A total of 20 experimental units were generated from CCD as shown in Table 1.

\subsection{Hydroxypropylation of Starch}

Modification of starch was performed according to Lawal et al., [4]. Starch (60 g, dry basis, d.b.) was added with $120 \mathrm{~mL}$ distilled water, followed by $12 \mathrm{~g}$ anhydrous sodium sulphate $\left(\mathrm{Na}_{2} \mathrm{SO}_{4}\right.$, Sigma-Aldrich, 239313, ACS). The slurry was homogenized with magnetic stirrer for $30 \mathrm{~min}$. The $\mathrm{pH}$ of the starch suspension was adjusted to the required value (Table 1) using $2 \mathrm{M} \mathrm{NaOH}$ (Systerm, SO460-70, AR) and propylene oxide (Merck, 1576945, USP) was added as etherifying agent with continuous stirring. The reaction was carried out with continuous agitation using the required 
temperature (Table 1) for $24 \mathrm{~h}$. At the end of the reaction, the suspension was neutralized $(1 \mathrm{M} \mathrm{HCl}$, Sigma-Aldrich, 320331, ACS) and washed with distilled water. The hydroxypropylated starch was recovered by drying at $40{ }^{\circ} \mathrm{C}$ until the moisture content was approximately $10 \%$. The powder was ground, sieved (100 mesh) and kept in air-tight container until further analysis.

\section{Table 1}

Independent variables and experimental design levels expressed in coded and actual values used for hydroxypropylation of Saba banana starch

\begin{tabular}{|c|c|c|c|c|c|c|}
\hline \multirow[t]{2}{*}{ Run } & \multicolumn{3}{|c|}{ Coded Value } & \multicolumn{3}{|c|}{ Actual Value } \\
\hline & $\begin{array}{l}\mathrm{A} \\
(\mathrm{pH})\end{array}$ & $\begin{array}{l}\text { B } \\
\text { (Propylene Oxide) }\end{array}$ & $\begin{array}{l}\text { C } \\
\text { (Temperature) }\end{array}$ & $\mathrm{pH}$ & $\begin{array}{l}\text { Propylene Oxide* } \\
\text { (\% v/w) }\end{array}$ & $\begin{array}{l}\text { Temperature } \\
\left({ }^{\circ} \mathrm{C}\right)\end{array}$ \\
\hline 1 & -1 & -1 & -1 & 10 & 5 & 35 \\
\hline 2 & 1 & -1 & -1 & 12 & 5 & 35 \\
\hline 3 & -1 & 1 & -1 & 10 & 15 & 35 \\
\hline 4 & 1 & 1 & -1 & 12 & 15 & 35 \\
\hline 5 & -1 & -1 & 1 & 10 & 5 & 45 \\
\hline 6 & 1 & -1 & 1 & 12 & 5 & 45 \\
\hline 7 & -1 & 1 & 1 & 10 & 15 & 45 \\
\hline 8 & 1 & 1 & 1 & 12 & 15 & 45 \\
\hline 9 & -1.682 & 0 & 0 & 9.32 & 10 & 40 \\
\hline 10 & 1.682 & 0 & 0 & 12.68 & 10 & 40 \\
\hline 11 & 0 & -1.682 & 0 & 11 & 1.58 & 40 \\
\hline 12 & 0 & 1.682 & 0 & 11 & 18.42 & 40 \\
\hline 13 & 0 & 0 & -1.682 & 11 & 10 & 31.6 \\
\hline 14 & 0 & 0 & 1.682 & 11 & 10 & 48.4 \\
\hline 15 & 0 & 0 & 0 & 11 & 10 & 40 \\
\hline 16 & 0 & 0 & 0 & 11 & 10 & 40 \\
\hline 17 & 0 & 0 & 0 & 11 & 10 & 40 \\
\hline 18 & 0 & 0 & 0 & 11 & 10 & 40 \\
\hline 19 & 0 & 0 & 0 & 11 & 10 & 40 \\
\hline 20 & 0 & 0 & 0 & 11 & 10 & 40 \\
\hline
\end{tabular}

* based on starch dry weight

\subsection{Chemical Composition}

A Halogen Moisture Analyzer (Mettler Toledo, HG53) was used to determine the moisture content of starch. $5 \mathrm{~g}$ of sample was weighed on the drying pan and the reading was taken after 5 minutes. Protein, fat and ash content of the starch was analysed according to AACC methods 08-01, 46-13 and 30-25, respectively [11].

\subsection{Molar Substitution}

Extent of hydroxypropylation was measured according to Ratnayake and Jackson [12] with slight modifications. $0.05 \mathrm{~g}$ of starch was added with $25 \mathrm{~mL}$ of $\mathrm{H}_{2} \mathrm{SO}_{4}(2 \mathrm{M}$, Systerm, SU710-70, AR) and hydrolyzed in a boiling water bath until a clear solution was obtained. The solution was cooled at room temperature and diluted to $100 \mathrm{~mL}$. After that, $1 \mathrm{~mL}$ of aliquot solution was pipetted into a 25 $\mathrm{mL}$ volumetric flask and immersed in an ice bath. $8 \mathrm{~mL}$ of concentration $\mathrm{H}_{2} \mathrm{SO}_{4}$ was added dropwise to the flask. After mixing, the flask was kept in a boiling water bath for $20 \mathrm{~min}$, followed by immediate cooling in an ice bath for $10 \mathrm{~min} .0 .60 \mathrm{~mL}$ of ninhydrin reagent (Sigma-Aldrich, 151173, ACS) was added into the flask, followed by thorough shaking and incubation $\left(25^{\circ} \mathrm{C}\right.$ water bath for $100 \mathrm{~min}$ ). The volume of the solution in the flask was made up to $25 \mathrm{~mL}$ with concentrated $\mathrm{H}_{2} \mathrm{SO}_{4}$ 
and mixed by inverting the flask several times. After $5 \mathrm{~min}$, the absorbance was read (Lambda 35, Perkin Elmer) at $590 \mathrm{~nm}$ against a reagent blank. A standard curve was prepared with an aliquote (1 $\mathrm{mL}$ ) of standard aqueous solutions containing $0,10,20,30,40$ and $50 \mu \mathrm{g}$ of propylene glycol (Merck, 1576708, USP) per $\mathrm{mL}$. The degree of hydroxypropylation was calculated based on the molecular weight ratios of propylene glycol and hydroxypropyl content

Hydroxypropyl group equivalents $=$ Amount of glycol $(\mu g) \times 0.7763$

The molar substitution (MS) was calculated using

$M S=\frac{(\text { weight of hydroxypropyl/59) }}{\text { (weight of starch } / 162)}$

where MS is defined as the level of substitution in terms of moles of monomeric unit (in the polymeric substituent) per mole of anhydroglucose unit.

\subsection{Pasting Properties}

Pasting properties of starch was investigated using a Rapid Visco Analyzer (RVA) (RVA-4, Newport Scientific) interfaced with a personal computer equipped with Thermocline Windows software version 3 (TCW3). $3 \mathrm{~g}$ of starch (d.b.) was added with corrected volume of distilled water (total water $=25 \mathrm{~mL}$ ) and subjected to the programmed heating and cooling cycle [13].

\subsection{Freeze-Thaw Stability}

Starch suspension $(5 \% \mathrm{w} / \mathrm{w})$ was heated at $95{ }^{\circ} \mathrm{C}$ under constant agitation for $30 \mathrm{~min}$. Approximately $8 \mathrm{~mL}$ of starch suspension was weighed into a pre-weighed centrifuge tube and centrifuged at $3000 \mathrm{rpm}$ for $10 \mathrm{~min}$ (Sorvall Biofuge Prime R, Thermo Scientific). After centrifugation, the supernatant was discarded and the sediment was subjected to successive freeze-thaw cycles. The alternate cycle started by freezing sample at $-20{ }^{\circ} \mathrm{C}(24 \mathrm{~h})$, followed by thawing at room temperature $(2 \mathrm{~h})$. A total of five freeze-thaw cycles were performed. The sample was centrifuged at the completion of each cycle ( $8000 \mathrm{rpm}$ for $15 \mathrm{~min}$ ), and the percentage of water separated was considered the extent of syneresis.

Syneresis $(\%)=\frac{\text { Weight of separated liquid from starch gel }(\mathrm{g})}{\text { Total weight of starch gel before centrifugation }(\mathrm{g})} \times 100$

\subsection{Thermal Properties}

Differential Scanning Colorimeter (Diamond DSC, Perkin Elmer) equipped with a thermal analysis data system (Pyris Manager) was used to determine the gelatinization parameters (onset temperature, $T_{0}$; peak temperature, $T_{p}$; conclusion temperature, $T_{c}$; enthalpy, $\Delta H$ ) of the samples. Indium was used to calibrate the DSC. Measurement was made on starch:water (1:4) (w/w). The hermetically sealed pan was kept at room temperature for $24 \mathrm{~h}$ to achieve equilibrium prior to the measurement. The sample was scanned from $30^{\circ} \mathrm{C}$ to $100{ }^{\circ} \mathrm{C}$ at $10^{\circ} \mathrm{C} / \mathrm{min}$, and an empty pan was used as the reference for the measurement. 


\subsection{Statistical Analysis}

Design Expert (Stat-Ease Corporation, Minneapolis) version 6.0.11 was used to analyze the data obtained. All the response variables were fitted by a second-order model in the form of quadratic polynomial equation as shown below

$Y=\beta_{o}+\sum \beta_{i} X_{i}+\sum \beta_{i j} X_{i} X_{j}+\sum \beta_{i i} X_{i}^{2}$

whereby $Y$ is the predicted response; $Y$ is a constant; $B_{o}$ is the linear coefficient; $b_{i}$ is the squared coefficient, $B_{i j}$ is the crossproduct coefficient, and $X_{i}$ is the factor.

The analysis of variance (ANOVA) was carried out to determine individual linear, quadratic and interaction regression coefficient. The significance of all the terms of polynomial equation was analyzed statistically by computing the $F$ value at $p<0.05$. The software was used to generate response surface and contour plots.

\subsection{Optimization and Validation of Model}

Optimization of hydrodypropylation of Saba banana starch reaction conditions was carried out using the Response Surface Methodology (RSM). The optimum values of the three independent variables were obtained by using the numerical method of the software. The contour plots of selected models were plotted and then overlapped to identify the desirable zone and to determine the optimum values. To validate the optimal reaction conditions, Saba banana starch was hydroxypropylated with the proposed optimal conditions and the relevant responses were measured to compare with the predicted values.

\section{Results and Discussions}

\subsection{Molar Substitution}

As shown in Table 1, the centre point ( $\mathrm{pH} 11,10 \% \mathrm{v} / \mathrm{w}$ propylene oxide, $40{ }^{\circ} \mathrm{C}$ ) was replicated six times, thus 15 different reaction conditions were used to produce the hydroxypropylated banana starches. Native Saba banana starch contained $11.2 \%$ moisture, $1.03 \%$ protein, $0.17 \%$ fat and $0.48 \%$ ash. After modification, the moisture content of starch samples varied between 8.9 to $10.8 \%$. The molar substitution (MS) of hydroxypropylated starches prepared in this study ranged between 0.059-0.148. The highest level of substitution obtained falls within the FDA guideline for maximum permissible level (MS not more than 0.2) for food applications [14]. Similar MS (0.07) was reported for hydroxylpropylated plantain starch [4] modified under similar condition with run 15 (MS = 0.071), except the $\mathrm{pH}$ used was slightly higher (11.5) than this experiment. Table 2 illustrates the coefficients of the regression model for the determination of MS. Linear model was found best fit the experimental data obtained $(p<0.01)$ with $79.03 \%$ of the variations was explained by the model. All three variables significantly $(p<0.05)$ influenced the MS in a positive direction, and thus increase any of the factors may lead to higher level of substitution in the starch molecules. Comparison of the regression coefficient values reveals that propylene oxide amount and reaction temperature exerted more pronounced effect than the reaction $\mathrm{pH}$ in influencing the MS of the modified samples. However, different finding was found for hydroxypropylation of waxy maize starch where the reaction temperature showed less effect on the extent of reaction than $\mathrm{pH}$ [15]. 
Figure 2 shows increase of propylene oxide and $\mathrm{pH}$ during hydroxypropylation led to higher MS. Higher concentration of propylene oxide increased the availability of the etherifying agent in the proximity of starch granules caused, hence resulting greater rate of collision between starch alkoxide and propylene oxide $[4,16]$. By increasing the propylene oxide from 3 to $9 \%$, the MS values for hydroxypropylated normal wheat starch, waxy wheat starch and waxy maize starch were reported to be $0.055-0.151,0.043-0.133$ and $0.049-0.139$ respectively [17].

\section{Table 2}

Regression coefficients for the determination of the molar substitution of hydroxypropylated Saba banana starch

\begin{tabular}{ll}
\hline Factor & Molar Substitution (MS) \\
\hline Intercept & 0.0810 \\
Linear & \\
A (pH) & $0.0097^{*}$ \\
B (propylene oxide) & $0.0130^{*}$ \\
C (temperature) & $0.0110^{*}$ \\
CV \% & 9.58 \\
$\mathrm{R}^{2}$ & 0.8327 \\
Adj R & 0.7903 \\
\hline
\end{tabular}

* Significant at $p<0.05$

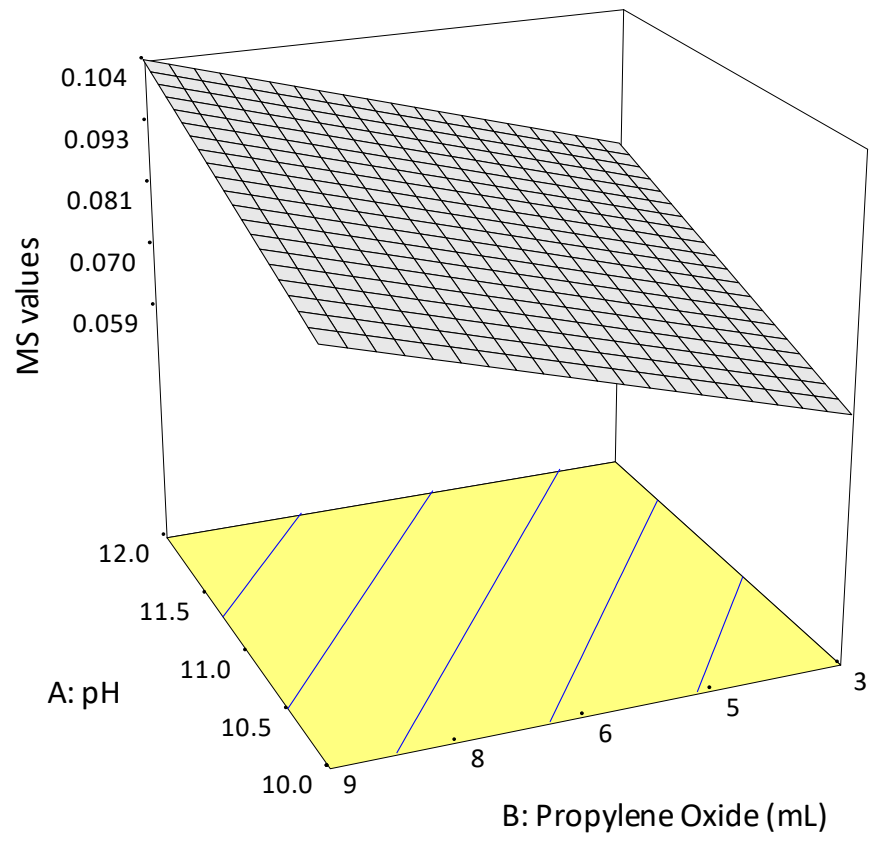

Fig. 2. Response surface plot of the effects of propylene oxide and $\mathrm{pH}$ on the molar substitution at $40^{\circ} \mathrm{C}$

Increase of $\mathrm{pH}$ during reaction promoted the alkalization of banana starch whereby $\mathrm{NaOH}$ reacted with the hydroxyl groups of the starch to produce more starch alkoxide to participate in the subsequent etherification step [18]. More alkaline conditions might also reduce starch polymer associations and open up granules to facilitate the modification [19]. It is speculated that increasing reaction temperature accelerated the reaction of starch with chemical reagent to an extent that reaction sites are concentrated in more accessible granule areas [15]. At elevated temperature, diffusion of the alkaline catalyst and the penetration of propylene oxide are facilitated [16]. 


\subsection{Pasting Properties}

Pasting properties describe the rheological characteristics right before, during and after the gelatinization of starch under continuous stirring using a fix temperature profile. After multiple regression analysis, the empirical relationship between response variables and the independent variables are shown in Table 3. It is interesting to find that the influence of the experimental variables on the pasting temperature and breakdown can be fitted by linear model, whereas quadratic model fitted the experimental data obtained for peak viscosity and setback. Comparing among the four responses, setback was found to be the only one affected by all the three independent variables of this study. The changes in pasting temperature, peak viscosity and breakdown were mainly attributed to the amount of propylene oxide used $(p<0.01)$. The influences of the three independent variables on the pasting parameters were not identical to the MS, even though the variations in these parameters were highly dependent on the MS. Results obtained suggest that the pasting parameters were not proportionately related to the degree of hydroxypropylation (MS) that took place in the starch. In the present study, there was no significant model could fit the data obtained for peak time (data not shown).

Table 3

Regression coefficients for the determination of the pasting parameters of hydroxypropylated Saba banana starch

\begin{tabular}{|c|c|c|c|c|}
\hline \multirow[t]{2}{*}{ Factor } & \multicolumn{4}{|l|}{ Pasting Parameters } \\
\hline & Pasting Temperature $\left({ }^{\circ} \mathrm{C}\right)$ & Peak Viscosity (cP) & Breakdown (cP) & $\begin{array}{l}\text { Setback } \\
\text { (cP) }\end{array}$ \\
\hline Intercept & $78.24^{*}$ & 4695.01 & $1077.37^{* *}$ & $992.62 * *$ \\
\hline \multicolumn{5}{|l|}{ Linear } \\
\hline $\mathrm{A}(\mathrm{pH})$ & -0.76 & -263.23 & 205.80 & $-339.04 * *$ \\
\hline B (propylene oxide) & $-1.77 * *$ & $348.06 *$ & $523.89 * *$ & $-484.13 * *$ \\
\hline C (temperature) & -0.17 & -165.48 & -123.18 & 65.06 \\
\hline \multicolumn{5}{|l|}{ Quadratic } \\
\hline$A^{2}$ & - & $-399.63 *$ & - & $89.81 *$ \\
\hline$B^{2}$ & - & 134.64 & - & $122.57 * *$ \\
\hline$C^{2}$ & - & -97.11 & - & $201.82 * *$ \\
\hline \multicolumn{5}{|l|}{ Interaction } \\
\hline$A B$ & - & 238.42 & - & -5.67 \\
\hline$A C$ & - & 41.00 & - & $153.33 * *$ \\
\hline $\mathrm{BC}$ & - & -50.33 & - & $-192.58 * *$ \\
\hline CV \% & 1.79 & 9.27 & 8.74 & 10.02 \\
\hline $\mathrm{R}^{2}$ & 0.8212 & 0.8812 & 0.8096 & 0.9703 \\
\hline Adj $R^{2}$ & 0.7557 & 0.7902 & 0.7781 & 0.9599 \\
\hline
\end{tabular}

* Significant at $\mathrm{p}<0.05$ and ${ }^{* *}$ significant at $\mathrm{p}<0.01$

Pasting temperature corresponds to the temperature at which gelatinization of starch begins [20]. Increase of propylene oxide had a negative linear effect (Figure 3 ) on the pasting temperature $(p<0.01)$, indicating starches with higher extent of modification required lower temperature for cooking. Hydroxypropylation altered the hydrophilicity of the starch polymer consequently changing the bonding of starch chains with water molecules. This led to an overall decline in bonding between starch chains, subsequently increasing the ease of hydration of starch chain [21].

Peak viscosity is related to the swelling power of starch granules, which is also an indicator of the extent of interaction between starch chains within the amorphous and crystalline region of starch granules [21]. This response was significantly affected by propylene oxide and negatively affected by the quadratic effect of $\mathrm{pH}(\mathrm{p}<0.05)$. The quadratic effect of $\mathrm{pH}$ appeared to be more 
pronounced and this effect is apparently seen in Figure 3, in which the peak viscosity increased to a maximum and dropped drastically when the $\mathrm{pH}$ was increased from $\mathrm{pH} 11$ to $\mathrm{pH} 12$. Comparatively, the increase of peak viscosity happened more gradually with increment of propylene oxide from 3 to $9 \mathrm{~mL}$ ( 5 to $15 \% \mathrm{w} / \mathrm{v}$ ). After modification, the hydroxyl groups in the starch were substituted with hydroxypropyl groups through a necleophilic substitution. The bulkier hydroxypropyl group can disrupt the inter- and intra-molecular forces in starch, consecutively weakened the starch granules, leading to increased rotational flexibility of starch amorphous regions, allowing in an increased water uptake and thus an increase in the swelling ability [22,23]. The introduction of hydrophilic hydroxypropyl groups might have exposed more hydrophilic $\mathrm{OH}$ groups already present in the starch granule thereby able to retain more amount of water [24]. Rice starches containing higher percent of hydroxypropyl groups were reported to have greater swelling power [21]. Hydroxypropylation also improved penetration of water into starch granules that enhanced amylose leaching, which also accounted for an increase in peak viscosity [16].
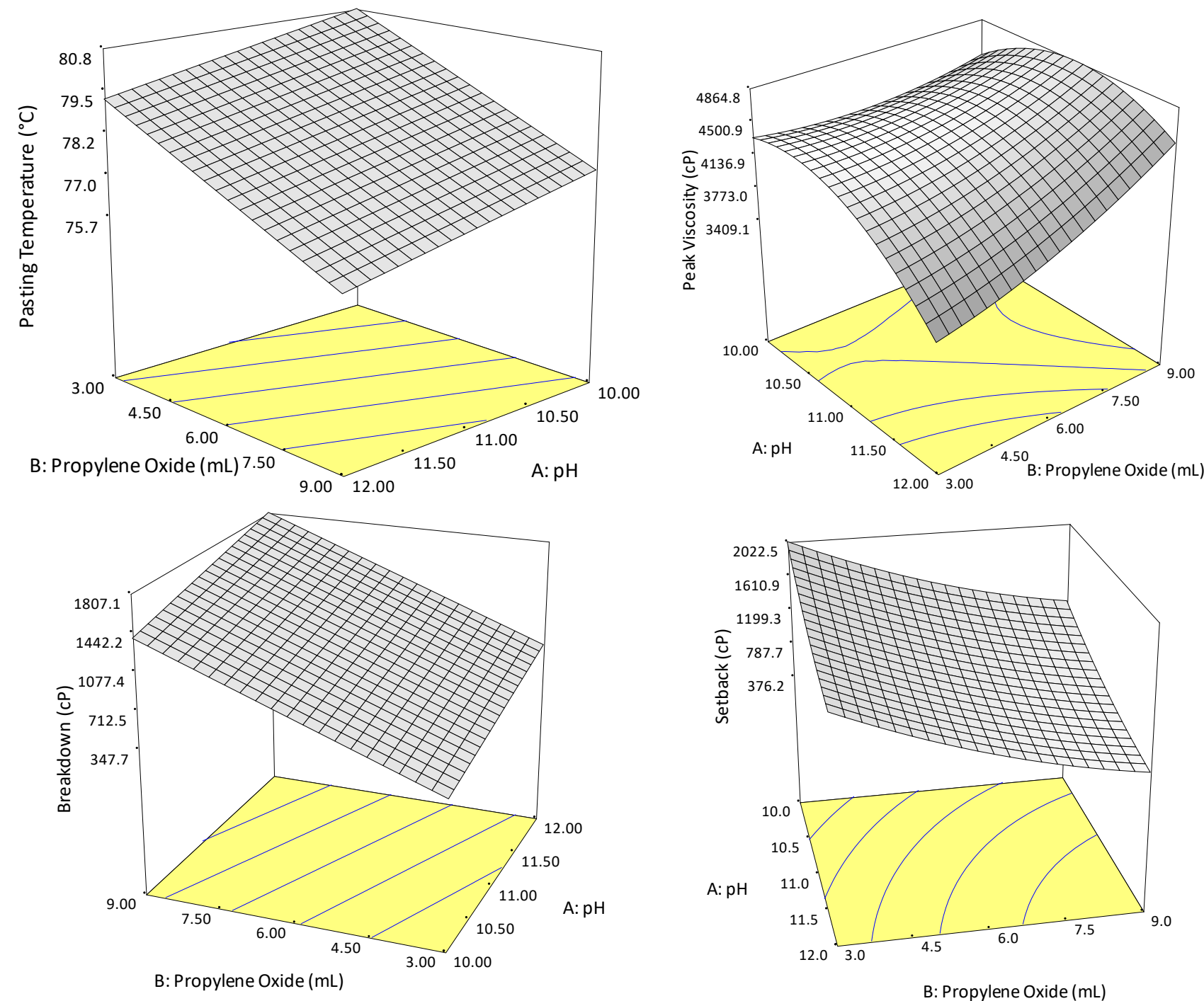

Fig. 3. Response surface plots of the effects of reaction $\mathrm{pH}$ and amount of propylene oxide $(\mathrm{mL})$ on the pasting temperature (reaction temperature of $40{ }^{\circ} \mathrm{C}$ ); peak viscosity (reaction temperature of $45{ }^{\circ} \mathrm{C}$ ); breakdown (reaction temperature of $40{ }^{\circ} \mathrm{C}$ ), and setback (reaction temperature of $40{ }^{\circ} \mathrm{C}$ ) for hydroxypropylated Saba banana starch 
Propylene oxide had major effect on breakdown $(p<0.01)$, in which breakdown increased linearly with increasing propylene oxide used in the treatment as shown in Figure 3. Breakdown measures the resistance of starch paste against shearing force at high temperature. Industrial applications favour starch with low breakdown as this implies less viscosity lost during heating and agitation in the processing. Results obtained indicate that higher level of hydroxypropylation may cause the swollen starch granules to be more fragile and tends to rupture. This is because starch with higher MS swelled to a relatively bigger volume, thus prompted the starch paste to greater breakdown. Setback implies the retrogradation tendency of a starch paste upon cooling. This response was significantly influenced by the negative effects of $\mathrm{pH}$ and propylene oxide $(\mathrm{p}<0.01)$; quadratic effects of all the three factors $(p<0.05)$; interactive effect of $\mathrm{pH}$ and temperature; as well as negative interactive effect of propylene oxide and temperature $(p<0.01)$. Among these factors, $\mathrm{pH}$ and propylene oxide appeared to be more prominent by displaying relatively higher regression coefficients (Table 3). The bulky hydroxypropyl group reduced the internal hydrogen bond strength and quantity in starch. This substantially decreased the ability of starch to recrystallize thus lowered the retrogradation of starch paste [25].

\subsection{Freeze-Thaw Stability}

Freeze-thaw stability of the starch was measured as the amount of water expelled (syneresis) from the thawed semi-solid starch gel under the action of centrifugal force. Syneresis from freezethawed gels is attributed to the increase of molecular association between starch chains at lower or freezing temperature which exudes water from the gel structure [16]. The empirical relationships between reaction factors and the freeze-thaw stability of hydroxypropylated banana starches were related by quadratic models (Table 4 ).

\section{Table 4}

Results of analysis of variance (ANOVA) of response surface quadratic model for syneresis of hydroxypropylated Saba banana starch at two cycles of freeze-thaw treatment

\begin{tabular}{lll}
\hline Factor & Syneresis & \\
\cline { 2 - 3 } & Cycle 1 & Cycle 5 \\
\hline Intercept & $8.14^{* *}$ & $20.47^{* *}$ \\
Linear & & \\
A (pH) & $-3.71^{* *}$ & $-4.49^{* *}$ \\
B (propylene oxide) & $-7.67^{* *}$ & $-6.59^{* *}$ \\
C (temperature) & -0.23 & $0.05^{*}$ \\
Quadratic & & \\
$A^{2}$ & 0.74 & -0.58 \\
$\mathrm{~B}^{2}$ & $1.01^{*}$ & $-1.69^{*}$ \\
$\mathrm{C}^{2}$ & $4.16^{* *}$ & $1.92^{*}$ \\
Interaction & & \\
$\mathrm{AB}$ & -0.71 & 0.16 \\
$\mathrm{AC}$ & $1.65^{*}$ & $2.35^{*}$ \\
$\mathrm{BC}$ & $-3.11^{* *}$ & $-2.23^{*}$ \\
$\mathrm{CV} \%$ & 11.18 & 10.03 \\
$\mathrm{R}^{2}$ & 0.8979 & 0.9408 \\
Adj $\mathrm{R}^{2}$ & 0.8691 & 0.9237 \\
\hline
\end{tabular}

* Significant at $\mathrm{p}<0.05$ and ${ }^{* *}$ significant at $\mathrm{p}<0.01$ 
Two polynomial equations were generated for the response at the first and the fifth freezethaw cycles for comparison. These two models were fitted to the spatial influence of the factors to the response with good prediction (Adj $R^{2}=0.97$ and 0.92). Though with slight different in the magnitude of influence (values of the coefficients), the ANOVA results for these two cycles indicate that the experimental factors influenced the response by similar model terms which involved the single terms of $\mathrm{pH}$ and propylene oxide $(\mathrm{p}<0.01)$; quadratic terms of propylene oxide and temperature $(p<0.05)$; the interactive terms of $\mathrm{pH}$ and temperature $(\mathrm{p}<0.05)$ as well as propylene oxide and temperature $(p<0.01)$. Data obtained evident that all three independent variables under study play significant role in improving the freeze-thaw stability of Saba banana starch. The negative effect of propylene oxide was more profound as indicated by the highest coefficient (Table 5). The reduction of syneresis with increasing propylene oxide is apparently seen in Figure 4.
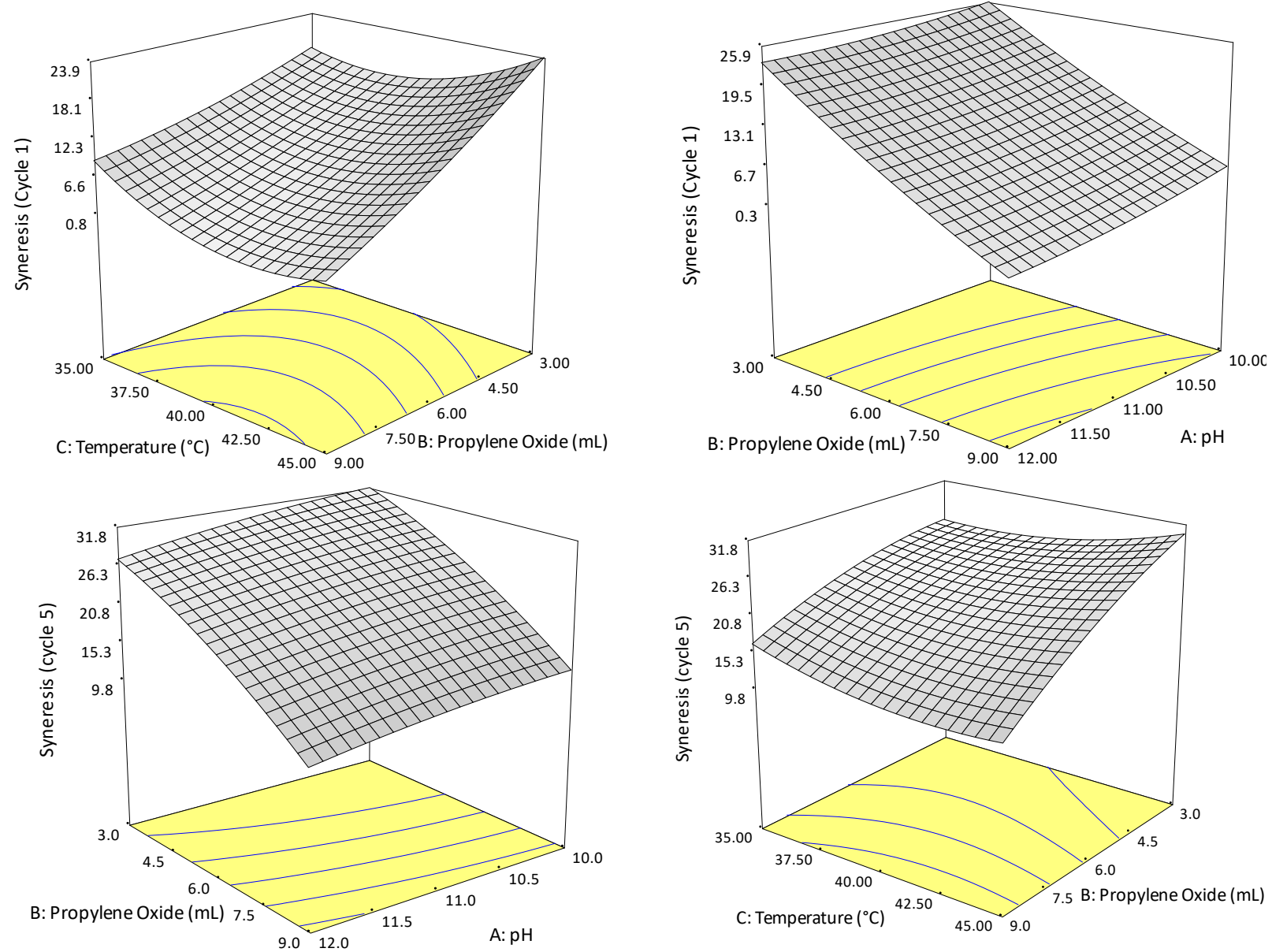

Fig. 4. Response surface plots of synereis (\%) of hydroxypropylate Saba banana starch at first freezethaw cycle (cycle 1) (top left at pH 11 and top right at $45^{\circ} \mathrm{C}$ ), and fifth freeze-thaw cycle (cycle 5) (bottom left at $45^{\circ} \mathrm{C}$ and bottom right at $\mathrm{pH}$ 10)

Significant reduction of syneresis of banana starch by hydroxypropylation was observed in which two modified starch with highest MS (0.148 and 0.116$)$ did not expelled any substantial amount of water after first and second freeze-thaw cycles. Similar findings was reported for freezethawed barley starch, whereby the \% syneresis at $10 \%$ hydroxypropylation was significantly lower than that at 5\% hydroxypropylation due to higher amount of substitution of hydroxypropyl groups [24]. The retrogradation was also found reduced as molar substitution of hydroxypropyl groups increased in normal wheat starch, waxy wheat starch and waxy maize starch [17]. The steric effects imposed by the bulky hydroxypropyl groups inhibited proper alignment of starch chains during 
chain aggregation and crystallization [26] thus minimized the water expelled. In general, the percentage of syneresis was observed to increase progressively as the number of freeze-thaw cycles increased. This was due to reorientation of the starch molecules after repeated freeze-thaw cycles and was therefore unable to hold the same amount of water as in the first cycle [24]. Freezethaw stability is a very vital property of starch that may widen the application in starch-based food products that require chilling or freezing storage. The reduction of syneresis implies better storage stability. It was reported that no water loss in custard made of hydroxypropylated pearl millet starch after seven days of cold storage [27].

Table 5

Results of analysis of variance (ANOVA) for gelatinization of hydroxypropylated Saba banana starch

\begin{tabular}{|c|c|c|c|c|}
\hline \multirow[t]{2}{*}{ Factor } & \multicolumn{4}{|c|}{ Gelatinization Properties } \\
\hline & $\mathrm{T}_{\mathrm{o}}\left({ }^{\circ} \mathrm{C}\right)$ & $\mathrm{T}_{\mathrm{p}}\left({ }^{\circ} \mathrm{C}\right)$ & $\mathrm{T}_{\mathrm{c}}\left({ }^{\circ} \mathrm{C}\right)$ & $\Delta H(\mathrm{~J} / \mathrm{g})$ \\
\hline Intercept & $69.64 *$ & 72.93* & 77.60 & 1.28 \\
\hline \multicolumn{5}{|l|}{ Linear } \\
\hline$A(p H)$ & -0.26 & -0.40 & -0.46 & -0.29 \\
\hline B (propylene oxide) & $-1.73 * *$ & $-1.72 * *$ & -1.70 & $-0.32 *$ \\
\hline $\mathrm{C}$ (temperature) & 0.29 & 0.007 & -0.26 & 0.33 \\
\hline \multicolumn{5}{|l|}{ Quadratic } \\
\hline$A^{2}$ & $1.08 *$ & $0.94 *$ & - & 0.002 \\
\hline$B^{2}$ & -0.06 & -0.46 & - & 0.09 \\
\hline $\mathrm{C}^{2}$ & 0.37 & 0.46 & - & $0.73^{* *}$ \\
\hline \multicolumn{5}{|l|}{ Interaction } \\
\hline$A B$ & -0.74 & -0.75 & - & 0.26 \\
\hline AC & 0.59 & 0.40 & - & 0.14 \\
\hline $\mathrm{BC}$ & -0.39 & -0.43 & - & 0.21 \\
\hline CV \% & 2.20 & 1.96 & 2.14 & 11.39 \\
\hline $\mathrm{R}^{2}$ & 0.8623 & 0.8694 & 0.4946 & 0.8394 \\
\hline Adj $R^{2}$ & 0.8434 & 0.8619 & 0.3999 & 0.8275 \\
\hline
\end{tabular}

\subsection{Thermal Properties}

The heating of starch suspensions in excess water and above a certain temperature causes an irreversible transition called gelatinization, which can be characterized by an endotherm obtained by differential scanning calorimeter (DSC). Quadratic models could be used to relate the factors to the onset temperature $\left(T_{0}\right)$, peak temperature $\left(T_{p}\right)$ and melting enthalpy $(\Delta H)$ of modified starches. However, no significant model was proposed for the conclusion temperature $\left(T_{c}\right)$. Hydroxypropylation of finger millet starches also reported to lower predominantly the $T_{o}$ and $T_{p}$ as compared to $T_{c}[16]$. Propylene oxide was found to lower the gelatinization temperatures, whilst the quadratic effect of $\mathrm{pH}$ on the other hand increased the temperatures. The higher coefficient values suggested etherifying agent exerted more dominant effect, as seen in the 3-D plots (Figure 5). Reduction of $T_{o}$ and $T_{p}$ with increasing propylene oxide happens to be more remarkable that the changes of the temperature parameters along with the increment of $\mathrm{pH}$. Hydroxypropylation is known to reduce the gelatinization temperature of starch. Two factors were proposed for the decrease in gelatinization temperatures of hydroxypropylated starches: (i) the addition of sodium hydroxide caused the defects to the starch crystallites during the reaction, and (ii) substituted hydroxypropyl groups led to the disruption of hydrogen bonds between starch chains, which 
improved the mobility of the starch chains and indirectly decreased the melting temperature of the starch crystallites [17]. Hydroxypropylation was also proposed as internal plasticization that promoted gelatinization and hence lowering melting temperature of starch [23].

The linear effect of propylene oxide and quadratic effect of reaction temperature significantly affected the enthalpy of hydroxypropylation Saba banana starch. The reduction of enthalpy is seen more apparent at reaction temperature around 37.5 and $41^{\circ} \mathrm{C}$, further increase of temperature raised the enthalpy. Increase of propylene oxide on the other hand decreased the enthalpy (Figure 5). The substituted hydroxypropyl groups disrupted the double helices because of the rotation of these flexible groups within the amorphous regions thus lowered the gelatinization enthalpy [28]. Generally, hydroxypropylation reduced the crystallinity of the starch granules and hence the enthalpy [17].
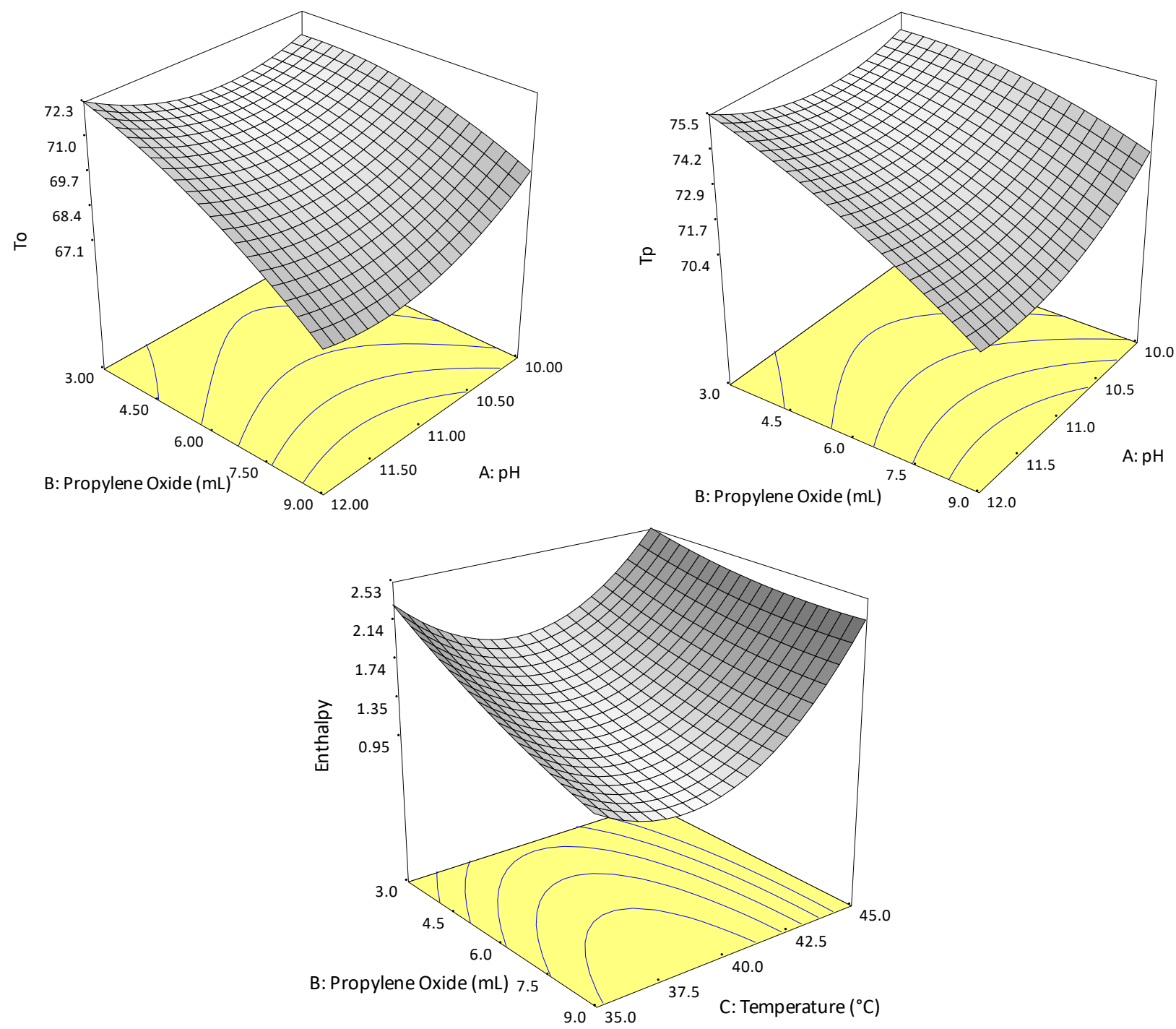

Fig. 5. Response surface plots of onset temperature, $\mathrm{T}_{\mathrm{o}}$ (at $40^{\circ} \mathrm{C}$ ); peak temperature, $\mathrm{T}_{\mathrm{p}}\left(40^{\circ} \mathrm{C}\right.$ ); and gelatinization enthalpy (at $\mathrm{pH} 11$ ) 


\subsection{Optimization and Verification}

Results obtained indicated $73.3 \%$ of the hydroxyproylated Saba banana starch produced (using 11 combinations of reaction condition) had lower peak viscosity than the native starch (data not shown). As peak viscosity is an indicator for the thickening ability of a starch, maximizing this technology functionality could provide wider scope of application for the modified starch. In order to produce modified banana starch with high thickening ability and high stability against retrogradation, MS, peak viscosity, setback and syneresis (both cycles) were chosen to optimize the reaction condition for hydroxypropylation of Saba banana starch. Results obtained also indicated that the range of the levels used for three investigated factors in this study could produce hydroxypropylated starch with lower thermal properties as compared to the native counter-part (data not shown); and because of thermal properties was not the main targeted functionality, this response was therefore not chosen for optimization. The criteria for the responses were fixed: MS was fixed to achieve the highest possible degree of substitution; peak viscosity was fixed to achieve the maximum possible viscosity; whereas setback and syneresis were fixed to attain the lowest possible values. The optimum conditions proposed was reaction $\mathrm{pH}$ at $12,15 \% \mathrm{v} / \mathrm{w}(9 \mathrm{~mL})$ of propylene oxide, and reaction temperature at $41.49{ }^{\circ} \mathrm{C}$. The desirability for this optimal condition was 0.812 . To confirm the optimal reaction conditions, Saba banana starch prepared under the optimal conditions was subjected to determination of MS, pasting properties, freeze-thaw stability ( 1 cycle) and thermal properties. Results obtained was comparable to the predicted values with the CV (coefficient of variation) ranged from 0.32 to $5.43 \%$ [29] (Table 6). The hydroxypropylated Saba banana starch prepared with the optimal conditions was also found to have improved properties as compared to its native counterpart. Besides apparently low in retrogradation tendency, it also exhibited lower gelatinization temperatures and lower enthalpy. The peak viscosity for these two samples was comparable.

\section{Table 6}

Experimental data of the validation of predicted values at optimal hydroxyrpopylation conditions and properties of native Saba banan starch

\begin{tabular}{|c|c|c|c|c|}
\hline Response & Predicted value & Experimental value & CV \% & Native starch \\
\hline Molar substitution (MS) & 0.158 & 0.153 & 3.16 & - \\
\hline \multicolumn{5}{|l|}{ Pasting properties: } \\
\hline Peak viscosity (cP) & 4692.36 & $4637.33 \pm 40.5$ & 1.17 & $4796.00 \pm 37.21$ \\
\hline Setback (cP) & 401.89 & $412.38 \pm 20.11$ & 2.61 & $1774.91 \pm 41.08$ \\
\hline Pasting temperature $\left({ }^{\circ} \mathrm{C}\right)$ & 75.66 & $75.90 \pm 13.86$ & 0.32 & $80.84 \pm 0.92$ \\
\hline Breakdown (cP) & 1770.25 & $1690.74 \pm 51.43$ & 4.49 & $808.26 \pm 30.37$ \\
\hline \multicolumn{5}{|l|}{ Freeze -thaw stability: } \\
\hline \% Syneresis (C1) & -2.33 & N.D & - & $21.3 \pm 2.1$ \\
\hline \multicolumn{5}{|l|}{ Thermal properties: } \\
\hline Onset temperature $\left({ }^{\circ} \mathrm{C}\right)$ & 67.56 & $66.98 \pm 0.25$ & 0.86 & $73.43 \pm 0.77$ \\
\hline Peak temperature $\left({ }^{\circ} \mathrm{C}\right)$ & 70.57 & $69.87 \pm 0.29$ & 0.99 & $77.11 \pm 0.04$ \\
\hline Conclusion temperature $\left({ }^{\circ} \mathrm{C}\right)$ & 75.36 & $74.51 \pm 0.52$ & 1.13 & $81.41 \pm 2.56$ \\
\hline Enthalpy (J/g) & 1.29 & $1.36 \pm 0.03$ & 5.43 & $3.19 \pm 0.20$ \\
\hline
\end{tabular}

\section{Conclusions}

Optimization of reaction conditions for hydroxypropylation of Saba banana was successfully carried out and the optimal reaction $\mathrm{pH}$, reaction temperature and the amount of propylene oxide required had been identified. The optimal condition was validated and found to be fitted with the experimental values. In general, the amount of propylene oxide used had more pronounced 
influence than reaction $\mathrm{pH}$ and reaction temperature in affecting the $\mathrm{MS}$ and other functional properties of hydroxypropylated Saba banana starch. Saba banana starch prepared under the optimal conditions shown improved functional properties than native Saba banana whereby it exhibited ease of cooking, low retrogradation and higher freeze-thaw stability. These positive properties could definitely turn Saba banana starch into a useful technological functional ingredient and hence widen its application in food industry.

\section{Acknowledgement}

This work is financially supported by the research fund of Universiti Malaysia Sabah (SDN00382019).

\section{References}

[1] Tumin, S. A., and A. A. Ahmad Shaharudin. "Banana: The world's most popular fruit." Khazanah Research Institute (2019).

[2] Zhang, P., R. L. Whistler, J. N. BeMiller, and B. R. Hamaker. "Banana starch: production, physicochemical properties, and digestibility-a review." Carbohydrate polymers 59, no. 4 (2005): 443-458. https://doi.org/10.1016/i.carbpol.2004.10.014

[3] Khoozani, A. A., B. Kebede, and A. E-D A. Bekhit. "Rheological, textural and structural changes in dough and bread partially substituted with whole green banana flour." LWT (2020): 109252.

https://doi.org/10.1016/i.lwt.2020.109252

[4] Lawal, O. S., O. O. Ogundiran, K. Awokoya, and A. O. Ogunkunle. "The low-substituted propylene oxide etherified plantain (Musa paradisiaca normalis) starch: Characterization and functional parameters." Carbohydrate Polymers 74, no. 3 (2008): 717-724. https://doi.org/10.1016/j.carbpol.2008.04.039

[5] Fan, Y., and F. Picchioni. "Modification of starch: a review on the application of "green" solvents and controlled functionalization." Carbohydrate Polymers (2020): 116350.

https://doi.org/10.1016/j.carbpol.2020.116350

[6] Fu, Z., L. Zhang, M-H Ren, and J. N. BeMiller. "Developments in Hydroxypropylation of Starch: a review." StarchStärke 71, no. 1-2 (2019): 1800167. https://doi.org/10.1002/star.201800167

[7] Lee, J. S., and P. C-S Loh. "Hydroxypropylation of Saba Banana Starch." In 3rd International Conference on Chemical, Biological and Environmental Engineering (IPCBEE), vol. 20, pp. 56-60. 2011.

[8] Nasri, W., R. Djebali, M. Goodarzi, M. A. Abbassi, and S. Abboudi. "Apple convective drying - Part II: Scrutinization of monitoring parameters levels via Taguchi optimization approach. " CFD Letters 11, no. 3 (2019): 42-54.

[9] Mohd Radzi, A. Q., and N. M. Samsuddin. "Design optimization of savonius wind turbine using CFD-particle swarm optimization with power flow validation experimentally. " CFD Letters 12, no. 10 (2020): 27-39. https://doi.org/10.37934/cfdl.12.10.2739

[10] Nimsung, P., M. Thongngam, and O. Naivikul. "Compositions, morphological and thermal properties of green banana flour and starch." Agriculture and Natural Resources 41, no. 5 (2007): 324-330.

[11] American Association of Cereal Chemists. "Approved methods of analysis." Brabender Quadrumat Jr.(Quadruplex) Method. Approved 16 Oct. 1991 (2000).

[12] Ratnayake, W. S., and D. S. Jackson. "Phase transition of cross-linked and hydroxypropylated corn (Zea mays L.) starches." LWT-Food science and technology 41, no. 2 (2008): 346-358. https://doi.org/10.1016/j.lwt.2007.03.008

[13] Ng, J-Q, C. K. Siew, H. Mamat, P. Matanjun, and J-S Lee. "Effect of Acid Methanol Treatment and Heat Moisture Treatment on In Vitro Digestibility and Estimated Glycemic Index of Raw and Gelatinized Sago (Metroxylon Sagu) Starch." Starch-Stärke 70, no. 9-10 (2018): 1700198.

https://doi.org/10.1002/star.201700198

[14] Chuenkamol, B., C. Puttanlek, V. Rungsardthong, and D. Uttapap. "Characterization of low-substituted hydroxypropylated canna starch." Food hydrocolloids 21, no. 7 (2007): 1123-1132. https://doi.org/10.1016/i.foodhyd.2006.08.013

[15] Gray, J. A., and J. N. BeMiller. "Influence of reaction conditions on the location of reactions in waxy maize starch granules reacted with a propylene oxide analog at low substitution levels." Carbohydrate Polymers 60, no. 2 (2005): 147-162. 
https://doi.org/10.1016/j.carbpol.2004.11.032

[16] Lawal, O. S. "Starch hydroxyalkylation: Physicochemical properties and enzymatic digestibility of native and hydroxypropylated finger millet (Eleusine coracana) starch." Food hydrocolloids 23, no. 2 (2009): 415-425. https://doi.org/10.1016/i.foodhyd.2008.02.013

[17] Wang, W., and Y-C Shi. "Gelatinization, pasting and retrogradation properties of hydroxypropylated normal wheat, waxy wheat, and waxy maize starches." Food Hydrocolloids (2020): 105910. https://doi.org/10.1016/i.foodhyd.2020.105910

[18] Rachtanapun, P., P. Simasatitkul, W. Chaiwan, and Y. Watthanaworasakun. "Effect of sodium hydroxide concentration on properties of carboxymethyl rice starch." International Food Research Journal 19, no. 3 (2012): 923.

[19] Han, J-A, and J. N. BeMiller. "Influence of reaction conditions on MS values and physical properties of waxy maize starch derivatized by reaction with propylene oxide." Carbohydrate polymers 64, no. 2 (2006): 158-162. https://doi.org/10.1016/i.carbpol.2005.11.008

[20] Schirmer, M., M. Jekle, and T. Becker. "Starch gelatinization and its complexity for analysis." Starch-Stärke 67, no. 1-2 (2015): 30-41. https://doi.org/10.1002/star.201400071

[21] Moin, A., T. M. Ali, and A. Hasnain. "Characterization and utilization of hydroxypropylated rice starches for improving textural and storage properties of rice puddings." International journal of biological macromolecules 105 (2017): 843-851. https://doi.org/10.1016/i.ijbiomac.2017.07.109

[22] Ju, B., D. Yan, and S. Zhang. "Micelles self-assembled from thermoresponsive 2-hydroxy-3-butoxypropyl starches for drug delivery." Carbohydrate polymers 87, no. 2 (2012): 1404-1409. https://doi.org/10.1016/i.carbpol.2011.09.028

[23] Seow, C. C., and K. Thevamalar. "Internal plasticization of granular rice starch by hydroxypropylation: Effects on phase transitions associated with gelatinization." Starch-Stärke 45, no. 3 (1993): 85-88. https://doi.org/10.1002/star.19930450303

[24] Devi, R., and N. Sit. "Effect of single and dual steps annealing in combination with hydroxypropylation on physicochemical, functional and rheological properties of barley starch." International journal of biological macromolecules 129 (2019): 1006-1014. https://doi.org/10.1016/i.ijbiomac.2019.02.104

[25] Pal, J., R. S. Singhal, and P. R. Kulkarni. "Physicochemical properties of hydroxypropyl derivative from corn and amaranth starch." Carbohydrate Polymers 48, no. 1 (2002): 49-53. https://doi.org/10.1016/S0144-8617(01)00209-0

[26] Perera, C., and R. Hoover. "Influence of hydroxypropylation on retrogradation properties of native, defatted and heat-moisture treated potato starches." Food Chemistry 64, no. 3 (1999): 361-375. https://doi.org/10.1016/S0308-8146(98)00130-7

[27] Shaikh, M., T. M. Ali, and A. Hasnain. "Utilization of chemically modified pearl millet starches in preparation of custards with improved cold storage stability." International journal of biological macromolecules 104 (2017): 360-366.

https://doi.org/10.1016/j.ijbiomac.2017.05.183

[28] Perera, C., R. Hoover, and A. M. Martin. "The effect of hydroxypropylation on the structure and physicochemical properties of native, defatted and heat-moisture treated potato starches." Food Research International 30, no. 34 (1997): 235-247.

https://doi.org/10.1016/S0963-9969(97)00041-0

[29] Belwal, T., P. Dhyani, I. D. Bhatt, R. S. Rawal, and V. Pande. "Optimization extraction conditions for improving phenolic content and antioxidant activity in Berberis asiatica fruits using response surface methodology (RSM)." Food Chemistry 207 (2016): 115-124. https://doi.org/10.1016/j.foodchem.2016.03.081 